\title{
PERBANDINGAN ANTARA KEKUATAN BAHU DAN KEKUATAN TUNGKAI PEMAIN BOLA VOLI DAN BOLA BASKET MAHASISWA IKIP PGRI PONTIANAK
}

Asmutiar $^{1}$, Mohammad Sabransyah ${ }^{2}$

${ }^{1}$ IKP PGRI Ponitianak, Indoensia

Rektorat Jl. Ampera No. 88 Pontianak - 78116 Telp./Fax. (0561)748219/6589855

asmu_tiar@yahoo.com, sabran.pjkr@gmail.com ${ }^{1}$

\begin{tabular}{l}
\hline Info Artikel \\
\hline Sejarah Artikel: \\
Diterima Maret 2020 \\
Disetujui April 2020 \\
Dipublikasikan Juni 2020
\end{tabular}

Abstrak
Permianan bola basket dan bola voli memiliki pola gerak dan
penggunaan bagian tubuh yang hampir sama dari kedua
teknik. Tetapi belum diketahui kekuatan bahu dan kekuatan
tungkai mana dari kedua cabang olahraga tersebut yang
memiliki kekuatan tinggi untuk melakukan teknik lompatan,
smass dan shooting. Penelitian ini untuk mengetahui ada atau
tidak perbandingan kekuatan bahu dan tungkai pemain bola
basket dan bola voli. Kausal Komparatif (causal comparative
research). Hasil tes push and pull Dynamometer pemain
basket dan voli, Nilai t hitung adalah -0.187 bulatkan nilai
tersebut dan bandingkan dengan t tabel. Nilai t hitung ( 0.187$)$
$<\mathrm{t}$ tabel 0,$05 ; 14=1.76131$ sehingga Ho diterima. Hasil tes Back
and Leg Dynamometer pemain basket dan voli, Nilai t hitung
adalah -0.604 bulatkan nilai tersebut dan bandingkan dengan $\mathrm{t}$
tabel. Nilai t hitung ( 0.604$)<\mathrm{t}$ tabel 0,$05 ; 14=1.76131$ sehingga
Ho diterima. Dengan demikian hipotesis yang menyatakan
apakah ada perbandingan antara kekuatan bahu dan kekuatan
tungkai pemain bola basket dan pemain bola voli mahasiswa
IKIP PGRI Pontianak, tidak diterima kebenarannya

Kata Kunci :

Bola basket, Bola Voli, push and pull Dynamometer, Back Abstrack

and Leg Dynamometer,

Kekuatan Bahu dan Tungkai

Keywoard:

Basketball, Volleyball, Push and

Pull Dynamometer, Back and

Leg Dynamometer, Shoulder

and Leg Strength

The game of basketball and volleyball has a pattern of motion and use of almost the same body parts from both techniques. But it is not yet known which shoulder strength and leg strength of the two sports branches have high strength to do the jumping, smass and shooting techniques. This research is to find out whether or not there is a comparison of the shoulder and limb strength of basketball and volleyball players. Causal Comparative (causal comparative research). Push and pull test results for basketball and volleyball players, the calculated $t$ value is -0.187 round the value and compare it with the t table. $T$ value (0.187) <t table 0.05; $14=1.76131$ so that Ho is accepted. Back and Leg Dynamometer test results for basketball and volleyball players, the calculated $t$ value is -0.604 round that value and compare it to the t table. $T$ value (0.604) <t table 0.05;14 $=1.76131$ so that Ho is accepted. Thus the hypothesis which states whether there is a comparison between shoulder strength and leg strength of basketball players and volleyball players of IKIP PGRI Pontianak students, is not accepte 


\section{PENDAHULUAN}

Perkembangan yang cukup pesat ditunjukkan untuk setiap cabang olahraga di Indonesia, ini dapat dilihat dari banyaknya pertandingan yang diselengarakan baik tingkat pelajar, mahasiswa dan masyarakat umum. (Haqiyah et al., 2017) Perencanaan yang matang diperlukan untuk membangun sebuah tim, dimana tim tersebut memiliki kemampuan teknik, taktik, strategi dan kondisi fisik yang baik demi mencapai prestasi tertinggi. Perencanaan yang dimaksud adalah latihan yang cukup lama kepada setiap pemain atau atlit untuk memiliki teknik, taktik, serta dapat memahami strategi yang diberikan oleh pelatih dan ada peningkatan terhadap kondisi fisik mereka.

Menurut (Suherly Dina Saputra \& Syamsul taufik, 2019) Latihan merupakan syarat mutlak dalam meningkatkan suatu keterampilan teknik dan kondisi fisik sampai menuju puncak prestasi. Latihan adalah salah satu faktor pendukung dalam rangka mencapai puncak keberhasilan seorang atlet. Atlet yang dapat mencapai puncak prestasi itu merupakan hasil dari suatu program yang terbentuk dari berbagai unsur yang diintegrasikan menjadi suatu pedoman latihan bagi atlet, sehingga hasil dari latihan tersebut bisa dipertanggung jawab kan. (Ganang Purnomo Aji, 2016) latihan yang sangat panjang terutama bagian fisik koordinasi. Dalam Kemajuan dan kemunduran prestasi atlet juga tergantung dari program latihan, dengan demikian pelatih harus mampu dan jeli akan kebutuhan atau kekurangan yang harus ditingkatkan dari atlet. Salah satu cara melihat kemajuan seorang atlet adalah dengan mengevaluasi secara objektif, transparan dan menyeluruh. Menurut (MS. Taufik, 2019)Usaha pencapaian puncak prestasi atlet tidaklah mudah, perlu suatu ketajaman pengetahuan dalam penyusunan program latihan, disamping itu pelatih harus mampu menguasai atlet secara psikologis sehingga atlet merasa nyaman dan termotivasi dalam berlatih. (Handayani, 2015) Proses perencanaan suatu program latihan haruslah mengacu kepada prosedur yang terorganisasi dengan baik (well organized), yang metodis, dan yang ilmiah, agar dengan demikian program tersebut bisa membantu atlet untuk mencapai prestasi yang setinggi- 
31 | Asmutiar ${ }^{1}$, Mohammad Sabransyah ${ }^{2}$

Perbandingan Antara Kekuatan Bahu Dan Kekuatan Tungkai Pemain Bola Voli Dan Bola Basket Mahasiswa Ikip Pgri Pontianak

tingginya. Jadi perencanaan program atau training plan merupakan alat yang penting bagi pelatih untuk bisa melaksanakan program secara well organized. Menurut (Rivan Syukur \& Kastrena, 2019) kemahiran pelatih dalam menyusun suatu program latihan yang baik, maka tidak mungkin pula dia bisa melaksanakan training secara terorganisasi dengan baik. Cabang olahraga bola voli dan bola basket menggunakan kondisi fisik yang hampir sama, menurut (Ambarwati et al., 2017) diantaranya menggunakan kekuatan otot, daya tahan otot, daya tahan pernapasan kardiovaskuler, fleksibilitas dan komposisi tubuh. Berdasarkan karakter gerak antara basket dan voli menggunakan kekuatan bahu untuk melakukan gerakan smash dalam bola voli dan shooting dalam bola basket, kemudian kekuatan tungkai kaki digunakan untuk gerakan melompat saat smash pada permainan bola voli dan gerakan lay up pada permainan bola basket. (Switri \& Yusfi, 2019)

Secara garis besar permainan Bola basket dilakukan dengan mempergunakan tiga unsur teknik yang menjadi pokok permainan, yakni : mengoper dan menangkap bola (pasing and catching), menggiring bola (dribbling), serta menembak (shooting), teknik latihan olah kaki (footwork) (Ahmadi, 2007 : 13). Permainan bola voli adalah bentuk permainan beregu yang mengandalkan keterampilan setiap pemain, maka dalam permainan ini memerlukan penguasaan teknik dasar sebaik mungkin agar dapat bermain dengan baik, maka perlulah kiranya setiap pemain secara perorangan berusaha meningkatkan penguasaan teknik dasar dalam permainan bola voli secara sempurna (Suharno, 1993 : 12). Berdasarkan pemaparan diatas, dapat dilihat bahwa ada pola gerak dan penggunaan bagian tubuh yang sama dari kedua teknik diatas. Tetapi belum diketahui kekuatan bahu dan kekuatan tungkai mana dari kedua cabang menurut (Faridhatunnisa \& Kurniawan Pratama, 2019) olahraga tersebut yang memiliki kekuatan tinggi untuk melakukan teknik lompatan, smass dan shooting. Oleh sebab itu, kami ingin melakukan penelitian tentang masalah "Perbandingan Antara Kekuatan Bahu Dan Kekuatan Tungkai Pemain Bola Voli Dan Bola Basket Mahasiswa Ikip Pgri Pontianak".

\section{METODE}

Penelitian ini menggunakan metode Kausal Komparatif (causal comparative research). Penelitian kausal komparatif 
32 | Asmutiar ${ }^{1}$, Mohammad Sabransyah ${ }^{2}$

Perbandingan Antara Kekuatan Bahu Dan Kekuatan Tungkai Pemain Bola Voli Dan Bola Basket Mahasiswa Ikip Pgri Pontianak

disebut juga penelitian ex post facto adalah penyelidikan empiris yang sistematis di mana ilmuwan tidak mengendalikan variable bebas secara langsung karena eksistensi dari variable tersebut pada dasarnya tidak dapat dimanipulasi (Emzir, 2012 : 119). Menurut Aswarni Sudjud (dalam Suharsimi Arikunto, 2006 : 267), mengatakan bahwa: "Penelitian Komparatif (perbandingan) akan dapat menemukan persamaan dan perbedaan tentang benda-benda, tentang orang, tentang prosedur kerja, tentang ide-ide, krirtik terhadap orang, kelompok, terhadap suatu ide atau suatu prosedur kerja.

Desain penelitian kausal komparatif menurut Gay (dalam Emzir, 2012 : 127), adalah sangat sederhana, dan walaupun variabel bebas tidak dimanipulasi, ada prosedur kontrol yang dapat diterapkan. Dalam penelitian ini tidak ada perlakuan, langsung pengambilan posttest (tes akhir). Desain dasar penelitian kausal komparatif (Gay dalam Emzir, 2012 : 127) sebagai berikut:

Tabel 1.1 Desain Penelitian

\begin{tabular}{|c|c|c|c|}
\hline Kasu & Kelomp & Variab & Variab \\
$\mathbf{s}$ & ok & el & Terika \\
& & Bebas & $\mathbf{t}$ \\
\hline
\end{tabular}

\begin{tabular}{|c|c|c|c|}
\hline $\mathrm{B}$ & $(\mathrm{E})$ & $\left(\mathrm{X}_{1}\right)$ & 0 \\
\hline & $(\mathrm{K})$ & $\left(\mathrm{X}_{2}\right)$ & 0 \\
\hline
\end{tabular}

Emzir (2012 : 128) menjelaskan bahwa Desain dasar penelitian kausal komparatif melibatkan pemilihan dua kelompok yang berbeda pada beberapa variabel bebas dan membandingkan mereka pada beberapa variabel terikat. Hasil analisis dinyatakan terdapat perbedaan jika nilai signifikansi kurang dari 0,05 $(\mathrm{P}<0,05)$.

Populasi dalam penelitian ini adalah seluruh pemain bola basket berjumlah 15 mahasiswa dan bola voli 15 mahasiswa yang tergabung dalam UKM Basket dan Voli. Mengukur kekuatan dan daya tahan otot lengan dan otot bahu yaitu dengan alat tes push and pull Dynamometer. Mengukur kekuatan tungkai adalah dengan menggunakan Back and Leg Dynamometer.

\section{HASIL DAN PEMBAHASAN}

Hasil Deskriptif Data Antar Kelompok

\begin{tabular}{|c|c|c|c|}
\hline \multicolumn{4}{|c|}{ Push Dynamometer } \\
\hline Kelompok & $\mathbf{N}$ & Rerata & $\begin{array}{c}\text { Rerata } \\
\text { Delta }\end{array}$ \\
\hline $\begin{array}{c}\text { Bola } \\
\text { Basket }\end{array}$ & 15 & 33.13333333 & 0,533333 \\
\hline Bola Voli & 15 & 33.66666667 & \\
\hline \multicolumn{4}{|c|}{ Leg Dynamometer } \\
\hline Kelompok & $\mathbf{N}$ & Rerata & $\begin{array}{c}\text { Rerata } \\
\text { Delta }\end{array}$ \\
\hline
\end{tabular}


33 | Asmutiar ${ }^{1}$, Mohammad Sabransyah ${ }^{2}$

Perbandingan Antara Kekuatan Bahu Dan Kekuatan Tungkai Pemain Bola Voli Dan Bola Basket Mahasiswa Ikip Pgri Pontianak

\begin{tabular}{|c|c|c|c|}
\hline $\begin{array}{c}\text { Bola } \\
\text { Basket }\end{array}$ & 15 & 69.53333333 & \multirow{2}{*}{2} \\
\cline { 1 - 2 } Bola Voli & 15 & 71.53333333 & \\
\hline
\end{tabular}

Hasil Paired T Test Push Dynamometer

Kelompok Basket dan Voli

Uji t- test

\begin{tabular}{|c|c|c|c|}
\hline Variabel & $t_{\text {hitun }}$ & $\begin{array}{c}\text { Signifika } \\
\text { nsi (p) }\end{array}$ & Status \\
\hline $\begin{array}{c}\text { Kekuatan } \\
\text { Tungkai }\end{array}$ & $\begin{array}{c}- \\
, 604\end{array}$ & 556, & $\begin{array}{c}\text { Tidak } \\
\text { Ada } \\
\text { Perban } \\
\text { dingan }\end{array}$ \\
\hline Variabel & $t_{\text {hitu }}$ & $\begin{array}{l}\text { Signifik } \\
\text { ansi (p) }\end{array}$ & Status \\
\hline $\begin{array}{c}\text { Kekuatan } \\
\text { Bahu }\end{array}$ & $\begin{array}{l}, 1 \\
87\end{array}$ & ,854 & $\begin{array}{c}\text { Tidak } \\
\text { ada } \\
\text { Perban } \\
\text { dingan }\end{array}$ \\
\hline
\end{tabular}

Nilai t hitung adalah -0.187 bulatkan nilai tersebut dan bandingkan dengan $\mathrm{t}$ tabel. Nilai t hitung $(0.187)<\mathrm{t}$ tabel 0,$05 ; 14=1.76131$ sehingga Ho diterima. Hasil perhitungan dari tabel diatas bisa di buat kesimpulan bahwa thitung lebih kecil dari ttabel dan nilai probabilitas diatas 0,05 , maka hipotesis nol diterima yang berarti tidak terdapat perbedaan rerata skor push dynamometer pemain bola basket dan pemain voli. Disimpulkan bahwa tidak terdapat perbandingan antara kekuatan bahu pemain bola basket dan pemain bola voli mahasiswa IKIP PGRI Pontianak.

Uji t- test Push Dynamometer Kelompok Basket dan Voli

Nilai t hitung adalah -0.604 bulatkan nilai tersebut dan bandingkan dengan $\mathrm{t}$ tabel. Nilai t hitung $(0.604)<\mathrm{t}$ tabel 0,$05 ; 14=1.76131$ sehingga $\mathrm{Ho}$ diterima. Hasil perhitungan dari tabel diatas bisa di buat kesimpulan bahwa thitung lebih kecil dari ttabel dan nilai probabilitas diatas 0,05 , maka hipotesis nol diterima yang berarti tidak terdapat perbedaan rerata skor leg dynamometer pemain bola basket dan pemain voli. Disimpulkan bahwa tidak terdapat perbandingan antara kekuatan tungkai pemain bola basket dan pemain bola voli mahasiswa IKIP PGRI Pontianak.

\section{KESEIMPULAN}

Tidak terdapat perbandingan antara kekuatan bahu pemain bola basket dan pemain bola voli mahasiswa IKIP PGRI Pontianak, dengan hasil perhitungan $(\mathrm{t}$ hitung $0.187<\mathrm{t}$ tabel 0,$05 ; 14=$ 1.76131). Tidak terdapat perbandingan antara kekuatan tungkai pemain bola basket dan pemain bola voli mahasiswa IKIP PGRI Pontianak, dengan hasil perhitungan $\mathrm{t}$ hitung $(0.604)<\mathrm{t}$ tabel 0,05;14 = 1.76131). Berdasarkan hasil penelitian diketahui bahwa, kekuatan 
34 | Asmutiar ${ }^{1}$, Mohammad Sabransyah ${ }^{2}$

Perbandingan Antara Kekuatan Bahu Dan Kekuatan Tungkai Pemain Bola Voli Dan Bola Basket Mahasiswa Ikip Pgri Pontianak

bahu dan kekuatan tungkai pemain bola basket dan pemain bola voli IKIP PGRI

Pontianak tidak memiliki perbandingan atau perbedaan yang signifikan setelah dilakukan uji secara statistik. Ini bisa terjadi jika bentuk latihan atau program latihan kedua cabang ini hampir sama dalam intensitas, durasi, dan repetisi.

Sehubungan dengan simpulan yang telah diambil dan implikasi kata yang ditimbulkan, maka disarankan bahwa Ada kecendrungan kemampuan bahu dan kemampuan tungkai pada mahasiswa IKIP PGRI Pontianak sama atau memiliki perbedaan yang sangat kecil yang disebabkan latihan dengan intensitas sama. Untuk meningkatkan kekuatan bahu dan kekuatan tungkai diperlukan latihan khusus terhadap kedua varibel tersebut.

\section{DAFTAR PUSTAKA}

Ahmadi, Nuril. 2007. Permainan Bolabasket. Surakarta: Era Intermedia

Arikunto, 2006. Prosedur Penelitian, Suatu Pendekatan Praktik.. Jakarta. PT Rineka Cipta.

Emzir, 2012. Metodologi Penelitian Pendidikan, Kuantitatif dan Kualitatif. Jakarta. Rajawali Pers.

Suharno, H.P. 1993. Ilmu Coaching
Umum. Yogyakarta. Direktorat

Keolahragaan

Ditjen

Diklusepora.

Ambarwati, D. R., Widiastuti, W., \& Pradityana, K. (2017). Pengaruh daya ledak otot lengan, kelentukan panggul, dan koordinasi terhadap keterampilan tolak peluru gaya O’Brien. Jurnal Keolahragaan, $5(2)$, 207. https://doi.org/10.21831/jk.v5i2.1 4918

Faridhatunnisa, F., \& Kurniawan Pratama, A. (2019). Peningkatan Latihan Kekuatan Otot Lengan Terhadap Hasil Servis Atas Bola Voli. Maenpo, 9(2), 76. https://doi.org/10.35194/jm.v9i2.9 11

Ganang Purnomo Aji. (2016). Pengembangan alat ladder untuk latihan koordinasi, kelincahan dan power (pp. 1-50).

Handayani, D. (2015). Pengaruh Latihan Interval Dan 10 Minute Triangle Run Terhadap Indeks Kelelahan.

Haqiyah, A., Mulyana, M., Widiastuti, W., \& Riyadi, D. N. (2017). The Effect of Intelligence, Leg Muscle Strength, and Balance Towards The Learning Outcomes of Pencak Silat with Empty-Handed Single 
35 | Asmutiar ${ }^{1}$, Mohammad Sabransyah ${ }^{2}$

Perbandingan Antara Kekuatan Bahu Dan Kekuatan Tungkai Pemain Bola Voli Dan Bola Basket Mahasiswa Ikip Pgri Pontianak

Artistic. JETL (Journal Of Suherly Dina Saputra, A., \& Syamsul Education, Teaching and taufik, M. (2019). Korelasi Antara Learning), 2(2), 211.

Motor Ability Dengan https://doi.org/10.26737/jetl.v2i2.288

MS. Taufik. (2019). Hubungan Tingkat

Konsentrasi Dengan Keterampilan

Bermain Futsal Unit Kegiatan

Mahasiswa Futsal Universitas

Suryakancana Dalam Olahraga.

Gladi Jurnal UNJ, 10(02), 68-78.

https://doi.org/10.21009/GJIK.102 .01

Rivan Syukur, M., \& Kastrena, E. (2019). Kontribusi Daya Ledak Otot Lengan Dan Daya Ledak Otot Tungkai Terhadap Hasil Smash. Maenpo, 9(1), 23. https://doi.org/10.35194/jm.v9i1.9 Keterampilan Dasar Bermain Bola Voli Pada Siswa Berusia 18-19. Maenpo, $\quad 9(1), \quad 30$. https://doi.org/10.35194/jm.v9i1.9 06

Switri, E., \& Yusfi, H. (2019). Pengembangan pembelajaran permainan bola voli pada mahasiswa The development of volleyball games learning for students Permenristekdikti no 44 tahun 2015 pasal 3 ayat 1 dan 2 , standar Nasional Pendidikan Tinggi bertujuan untuk menjamin tercapainya tujuan. 5.

05 